\title{
Intergenerational Transmission of Attitudes toward Poverty in Israel: A Comparison between Three Generations Families' of Jewish and Arab Social Work Students
}

\author{
Pnina Ron, Ph. D \\ ${ }^{1}$ Senior Lecturer, School of social work, Haifa University, Mount Carmel, Haifa, Israel \\ Correspondence: Pnina Ron, Senior Lecturer, School of social work, Haifa University, Mount Carmel, Haifa, Israel.
}

Received: February 3, 2015

Accepted: February 26, 2015

Available online: March 13, 2015

doi:10.11114/ijsss.v3i3.719

URL: http://dx.doi.org/10.11114/ijsss.v3i3.719

\begin{abstract}
Background: Given that many social workers in fact work with the economically disadvantaged, it may be assumed that their attitudes stem from their academic studies combined with attitudes acquired through intergenerational transmission. The study poses two main questions: 1) what are the attitudes of Israeli social work students, as well as those of their parents and their grandparents towards the causes of poverty? 2) How does each of the three generation' members approach the question "what is the best way for the state to deal with the problem of poverty?

Methods: The convenient sample consisted of 218 Arab and Jewish families, with three self-report questionnaires per family for the three generations.

Results: findings indicated that the majority of participants, in all three generations, considered the socio-structural factor to be the most significant cause of poverty. Similarly, most participants in this study also reported that they preferred that the state expand its welfare program and increase the budgets in order to assist the population in need and thus address the poverty problem.
\end{abstract}

Keywords: Poverty; Intergenerational transmission; Arab \& Jewish families; socio-structural factor

\section{Introduction}

Poverty is a broad concept that includes components factors of material disadvantages, perceived in terms of money or its equivalents, social opportunities (education, housing, welfare), and/or negative social stigmas (Davis \& Wainwright, 2005). Perceptions of and attitudes towards poverty affect the manner in which the difficulties of the poor are understood and defined, including the agents that caused their state of poverty and the agents responsible for helping them deal with their situation. The overall approach to the issue of poverty is -for the most part-socially based; it contributes to creating the political climate that regulates the degree of a society's humanization or dehumanization of poverty, and thus its feelings of sympathy or hostility, empathy or anomalism towards the poor themselves (Reeser \& Epstein, 1987; Rehner, 1997).

There are two main approaches to the concept of poverty: one considers the concept from an individualistic perspective, the other views it as a socially structured phenomenon (Bullock, Williams \& Limbert, 2003). The former is based on the deficit model, and understands poverty as the product of the individual's personal traits, which include lack of motivation, lack of perseverance, poor work ethics, etc. Considering such personal characteristics to be the main cause of poverty places the onus for poverty on the poor themselves. Accordingly, terms such as bad luck, severe disease or disability, fatalism, passivity, etc. are also associated with this group of individuals, and are perceived as paving the way to poverty (Schwarts \& Robinson, 1991; Sun, 2001). The second approach considers poverty to be a socially structured problem, hence its name: the social structural approach. According to this point of view, poverty is the product of social discrepancies, capitalist laissez-faire government (which abandons those who do not survive the competition), discrimination and deprivation, political circumstances, residential area and immigration, lack of resources, etc. (Kilty \& Segal, 2003; Macarov, 2003; Weiss, Gal \& Dixon, 2003). Poverty is thus the product of governments' economic and social policies as well as combination with globalization processes, and therefore the government should be held responsible for dealing with the problems of the poor.

Both the public in general and research professionals in particular agree that both approaches maintain the notion of 
"perpetual poverty". Consequently, the condition of poverty and the culture of poverty are passed from one generation to the next, by means of intergenerational transmission of values, attitudes and behavior patterns that are markedly different from those of the rest of society (Segal, 2007).

The extension of these two main attitudes encompasses also the approaches for dealing with poverty and assuming responsibility for aiding the poor. The individualistic approach places the responsibility for both the cause and the solution on the individual himself/herself; the social structural approach relegates responsibility for dealing with poverty and helping the poor to society, the same agent that created the circumstances which led these individuals to poverty in the first place (Spicker, 2007).

Intergenerational transmission is a term used to describe a broad spectrum of family relationships. Researchers have used it to refer to the process of transference of psychological characteristics from one generation to the next, which creates intergenerational similarities (Amto, 1996; Wolfinger, 2000; Ron, 2014). This type of transmission can be related include to beliefs, norms, values, attitudes and behavior patterns that are either family-specific or are influenced by the family's culture, religion and nationality (Ijzendoom, 1992; Hammen, Shih \& Brennan, 2004). Other researchers have found that various interpersonal characteristics, such as self-identity, self-esteem, and intergenerational dependence (Lawson \& Brossart, 2001), are subject to intergenerational transmission; even moods, such as depression in the grandmother and mother, have been found to be transmitted to the granddaughter (Hammen, Shih \& Brennan, 2004).

The current study poses two main questions: 1) What are the attitudes of Israeli Jewish and Arab social work students, as well as those of their parents and their grandparents towards the causes and agents of poverty, and to whom do they assign the responsibility of coping effectively with this problem? 2) What are the main demographic variables that affect the attitudes of all three generations towards poverty and how does each generation approach the question "what is the best way for the state to deal with the problem of poverty?

\section{Methods}

2.1 Sample

Data were gathered over a two year period (2008-2010). Participants in the sample were studying for a degree at the School of Social Work, Haifa University, Israel: 147 were undergraduates in their senior year and 94 were graduate students pursuing an MA degree in social work.

Students were asked to fill out an attitudes questionnaire in triplicate: once providing their own individual responses and the second and third questionnaires providing the responses of a parent and a grandparent, respectively, whom they had interviewed. (Ideally, all three participants of a single family were to be of the same gender). Of the 241 triplicate sets of questionnaires, 23 were disqualified: 8 because they did not represent three different generations, 11 were incomplete, and the rest were disqualified as students misunderstood instructions on choosing interviewees (e.g., the sister of a student's deceased grandmother). After these exclusions, the sample consisted of 218 families, with three questionnaires per family. Demographic information for the study sample is presented in Table 1.

Table 1. Background characteristics of the three study's generations $(\mathrm{N}=654)$

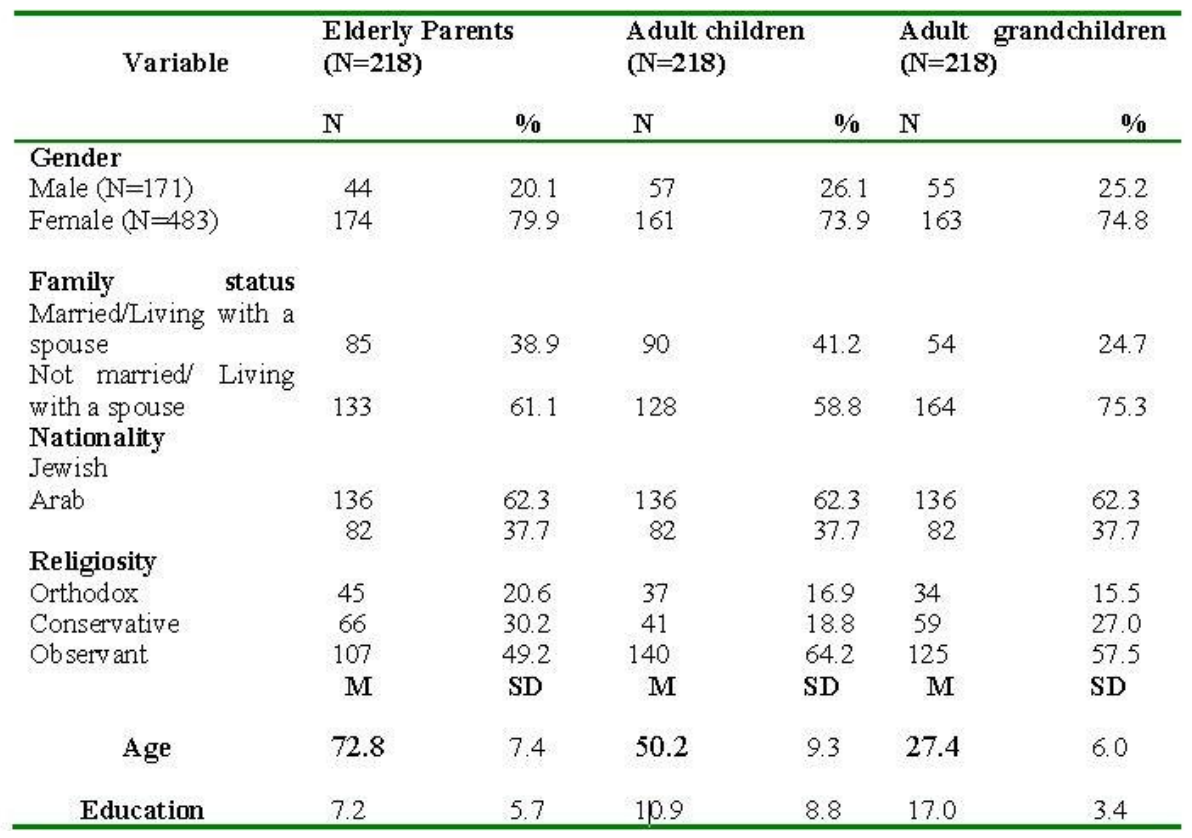


As shown in Table 1, the majority of participants (between $74 \%$ among the middle-age generation and $80 \%$ among the elderly parent generation) were females, which is typical of the gender distribution among social work students both in Israel and abroad. About two-third were Jews and most of participants were observant (between $49 \%$ among the elderly generation and $64 \%$ among their sons and daughter).

2.2 Tools-Background characteristics were assessed using a questionnaire devised specifically for the purpose of this study.

* Reasons for poverty variables were assessed using the tool of Weiss, I., Gal, J. \& Dixson, J. (2003), which includes 17 items, each of which presents a different cause of poverty. Participants were required to indicate their agreement level with the statement in each item, using a 5 point Likert-scale, ranging from 1 (completely agree) to 5 (completely disagree). For example: "Poverty is most often the outcome of emotional or mental difficulties."

A factor analysis of principal components of the 17 items found three main factors that explained $55 \%$ of the covariance: 1) the factor that explains poverty in social terms; 2) the factor that links poverty to an individual's emotional or mental problems; 3) the factor that links poverty to individual responsibility. These factors coincide with those found in Weis's original study, and their internal reliability ratings in the current study were also similar to those in the Weis study: .80, .81, and .84 Cronbach's alpha for factors 1,2 , and 3, respectively, in the current study, compared to .78, .81, and .82 Cronbach's alpha for factors 1,2 , and 3 , respectively, in the original study.

* To assess the official ways in which the state could deal with poverty, the tool of Weis et al. (2003) was used with 15 items, each of which represents a single manner in which the state could deal with poverty. Participants were asked to indicate their agreement with the statement in each item, using a 5 point Likert-scale, ranging from 1 (completely agree) to 5 (completely disagree). An example of an item statement is: "If the state invested more money in welfare, the problem of poverty would be resolved."

A factor analysis was conducted, to identify the principal components of the 15 items. As in the study of Weis et al., in the current study, three main factors were found to explain 64\% of the covariance: 1) the first was to expand programs and increase the amounts of welfare payments and benefits granted by the state; 2) the second factor was to provide psychological healthcare to the poor; 3) the third factor was to decrease the amounts granted as welfare payments so as to create greater economic incentives for the poor to join the job market. The internal reliability ratings for these factors did not coincide with those found in Weis's original study (2003): rates in the current study were .81, .84, and .85 Cronbach's alpha for factors 1, 2, and 3, respectively, compared to .79, .83, and .83 Cronbach's alpha for factors 1,2 , and 3, respectively, in Weis's original study.

* Sense of mastery was evaluated using an instrument constructed by Pearlin and colleagues (Pearlin, Menaghan, Lieberman, \& Mullan, 1981). The instrument includes seven items ranked on a five-point Likert-scale, ranging from 1 (completely disagree) to 5 (completely agree). Cronbach's alpha was .72 in general, and .77 in the current study.

\subsection{Statistical Analysis}

Statistical analysis was conducted in several stages. The first stage examined frequency of averages and standard deviations in all of the study variables in regard to the three generations sampled. In the second stage, repeated measures analysis of variance (ANOVA) was conducted, to determine whether there were differences among the three generations' perceptions of the causes of and the solutions for the problem of poverty. Therefore, paired comparisons were conducted, according to the Newman-Kuels test. Finally, in the third stage, a multivariate analysis of variance (MANOVA) was conducted to determine for each variable, which of the three generations demonstrated a significant difference.

\section{Results}

\subsection{Perceptions of the Causes of Poverty}

Significant differences were found, as shown in Table 2.

Table no. 2 indicates that all three generations favored the factor that explains poverty in social terms over the other two factors, i.e., the emotional explanation and the motivational explanation). In addition, between the two remaining factors, the grandparents' generation preferred the explanation that links individuals' emotional or mental state with poverty, whereas neither the parents nor the students' generations demonstrated any preference between the two.

A one-way MANOVA was conducted, comparing the importance attributed by each generation to each of the three causes of poverty, $(F(19,165)=9.02 ; p<.01)$. A univariate ANOVA was conducted to determine the source of these differences (see the two bottom rows in Table 2). Findings indicate significant differences regarding each of the three causes. 
Table 2. The three generations attitudes towards the reasons and explanations for the poverty phenomenon: means, standard deviation and diversity

\begin{tabular}{|c|c|c|c|c|c|c|c|c|c|}
\hline \multirow[t]{2}{*}{ Variable } & \multicolumn{2}{|l|}{$\begin{array}{l}\text { Social } \\
\text { Factor }\end{array}$} & \multicolumn{2}{|c|}{$\begin{array}{l}\text { Mental- } \\
\text { Emotional } \\
\text { Factor }\end{array}$} & \multicolumn{2}{|c|}{$\begin{array}{l}\text { Motivation } \\
\text { Factor }\end{array}$} & \multirow[t]{2}{*}{ F } & \multirow[t]{2}{*}{ Eta 2} & \multirow[t]{2}{*}{ SNK } \\
\hline & M & SD & M & SD & M & SD & & & \\
\hline Grandparents & 3.94 & 0.49 & 3.90 & 0.55 & 3.74 & 0.67 & $416.62^{*}$ & .84 & $1>2,3$ \\
\hline Adult children & 3.61 & 0.62 & 3.82 & 0.46 & 3.79 & 0.48 & $383.13^{*}$ & 77 & $1>2>3$ \\
\hline Grandchildren & 3.83 & 0.44 & 3.79 & 0.61 & 3.77 & 0.63 & $397.52^{*}$ & 73 & $1>2>3$ \\
\hline$F(3,466)$ & $11.09^{*}$ & & $14.64^{*}$ & & $14.98^{\circ}$ & & & & \\
\hline Eta 2 & .08 & & .0 & & & & & & \\
\hline
\end{tabular}

To assess gender differences in attitudes towards poverty and its causes, a MANOVA ( 2 genders X 3 generations) was conducted. Findings indicate significant differences between male and female participants $(F(4,287)=14.73 ; p<.01)$ : in all three generations, women preferred the explanation of social causes of poverty to the other two (emotional and motivational) explanations.

An additional MANOVA was conducted to determine whether there were differences between Jewish and Arab participants' perceptions of the causes of poverty ( 2 nationalities X 3 generations). Findings indicate significant perceptual differences between the two nationalities $(F(3,331)=19.17 ; p<.01)$. All three generations of Jewish participants preferred the social explanation of causes of poverty, whereas generally, the Arab participants in the current study preferred the emotional-mental causes of poverty to the social and motivational explanations, although the youngest generation of Arab participants preferred the social explanation $(p<.01)$.

Examining a possible correlation between degree of religiosity and the preferred explanation for the causes of poverty ( 3 degrees of religiosity X 3 generations) revealed a significant difference, indicating that secular participants preferred the social explanation to either of the other two possibilities $(F(5,472)=16.89 ; p<.01)$.

No significant correlation was found between personal status and a specific explanation for the causes of poverty $(F(17,772)=0.81 ; p<.05)$, or between level of education and a particular explanation for causes of poverty, assessed by means of a Pearson's test $(r=.31 ; p>.05)$. However, a significant difference was found between the youngest generation and the two older generations, as the former preferred the socio-structural explanation for the phenomenon of poverty $(r=.92 ; p<.01)$.

\subsection{Attitudes to and perceptions of the Ways of Dealing with the Poverty Phenomenon}

A significant difference between the three ways of dealing with poverty was found in all three generations. Averages, standard deviations, Eta2 values, and results of the paired comparisons conducted according to the Newman-Kuels test are presented in Table 3.

As table no. 3 shows, all three generations preferred dealing with the phenomenon of poverty by "expanding programs and increasing the amounts of welfare payments and benefits granted by the state." The second preferred approach was providing psychological therapy for the poor, and the least favored method was decreasing the amounts granted as welfare payments.

A one-way MANOVA found significant differences between the generations $(F(4,117)=12.92 ; p<.001)$. To assess gender differences in attitudes towards dealing with the phenomenon of poverty, a MANOVA was performed (2X3). Findings indicate significant differences between men and women $(F(4,279)=14.73 ; p<.01)$. Women of all three generations prefer to solve the problem of poverty by "expanding programs and increasing the amounts of welfare payments and benefits granted by the state," rather than by offering individual psychological therapy or reducing the amounts granted through welfare benefits. In contrast, the men's first choice was to reduce the amounts granted through welfare benefits as a means of solving the problem of poverty, followed by an equal distribution for the two remaining methods. 
Table 3. The three generations attitudes towards the ways of dealing with the poverty phenomenon: means, standard deviation and diversity

\begin{tabular}{|c|c|c|c|c|c|c|c|c|c|}
\hline \multirow[t]{2}{*}{ Variable } & \multicolumn{2}{|c|}{$\begin{array}{l}\text { Extension } \\
\text { welfare } \\
\text { programs }\end{array}$} & \multicolumn{2}{|c|}{$\begin{array}{l}\text { Personal } \\
\text { psychology } \\
\text { therapy }\end{array}$} & \multicolumn{2}{|c|}{$\begin{array}{l}\text { Reduction } \\
\text { welfare } \\
\text { program }\end{array}$} & \multirow[t]{2}{*}{ F } & \multirow[t]{2}{*}{ Eta 2} & \multirow[t]{2}{*}{ SNK } \\
\hline & M & SD & $\mathrm{M}$ & SD & M & SD & & & \\
\hline Grandparents & 3.72 & 0.70 & 2.08 & 0.72 & 1.70 & 0.66 & $428.07^{*}$ & .88 & $1>2>3$ \\
\hline Adult children & 3.58 & 0.53 & 1.98 & 0.84 & 2.94 & 0.75 & $417.44^{*}$ & .80 & $1>2>3$ \\
\hline Grandchildren & 3.95 & 0.44 & 1.71 & 0.79 & 2.0 & 0.62 & $398.13^{*}$ & .82 & $1>2>3$ \\
\hline$F(3,475)$ & \multicolumn{2}{|c|}{$14.14^{* * *}$} & \multicolumn{2}{|l|}{$20.23 *$} & \multicolumn{3}{|c|}{$17.84^{* k-k}$} & & \\
\hline Eta 2 & \multicolumn{2}{|l|}{0.17} & \multicolumn{2}{|l|}{0.13} & \multicolumn{3}{|l|}{0.14} & & \\
\hline
\end{tabular}

An additional MANOVA was conducted to determine whether there were differences between Jewish and Arab participants' perceptions of the best method for solving the problem of poverty (2X3). Findings indicate significant perceptual differences between the two nationalities $(F(3,831)=19.17 ; p<.01)$. Jewish participants of all three generations preferred to deal with the issue of poverty by expanding welfare programs; their second preference was to reduce the amounts granted through welfare benefits, and the least favored method was psychological therapy treatment $(p<.01)$. Interestingly, the first preference indicated by Arab participants for dealing with the issue of poverty was to reduce the amounts granted through welfare benefits, followed by expansion of welfare programs, and like their Jewish counterparts, their least favored approach was to provide personal psychological therapy treatment $(p<.05)$. Yet another interesting finding was the significant preference for dealing with poverty through the expansion of welfare programs indicated by the youngest generation of Arab participants. This population included graduate students in social work, meaning that they had already been trained and licensed to work as social workers in Israel $(p<.01)$.

Examining a possible correlation between degree of religiosity and the preferred method for dealing with the condition of poverty ( 3 X 3 ) revealed no significant difference, indicating that religiosity had no impact on the method preferred for addressing the problem of poverty $(F(4,108)=9.72)$.

Similarly, no significant correlation was found between personal status and any of the methods for addressing the issue of poverty $(F(9,117)=9.2)$. However, the Pearson's test did yield a significant correlation between level of education and the preferred method for dealing with the issue of poverty $(r=.38 ; p>.05)$.

\section{Discussion}

Over the last five decades, there have been numerous studies assessing the attitudes of social work students to the issue of poverty: it appears that the majority of students attribute the condition of poverty to social structural variables first, and only then to other personal variables (Weiss et al., 2002; Sun, 2001; Robinson, 1991). Given that many social workers in fact work with the economically disadvantaged, it may be assumed that their attitudes stem from their academic studies combined with attitudes acquired through intergenerational transmission.

Yet, the findings of the current study indicate that the majority of participants, in all three generations, considered the socio-structural factor to be the most significant cause of poverty. Similarly, most participants in this study also reported that they preferred that the state expand its welfare program and increase the budgets in order to assist the population in need and thus address the poverty problem.

The attitude demonstrated by these participants espouses the notion of social justice, as it links the difficulties experienced by needy individuals in society to the existing social structure. It is similar to the attitude held by the social workers' unions, in Israel as well as in many Western countries (BASW, 1996; NASW, 1994; 1999, 2002).

Given that all three generations demonstrated the same attitude, it is safe to assume that the dynamic of intergenerational transmission played an important function in yielding these findings.

The term "Intergenerational transmission" is used to describe a broad spectrum of family relationships. Researchers 
have used it to refer to the process of transference of psychological characteristics from one generation to the next, which creates intergenerational similarities (Amto, 1996; Wolfinger, 2000). This type of transmission can be related include to beliefs, norms, values, attitudes and behavior patterns that are either family-specific or are influenced by the family's culture, religion and nationality (Ijzendoom, 1992; Hammen, Shih \& Brennan, 2004). Other researchers have found that various interpersonal characteristics, such as self-identity, self-esteem, and intergenerational dependence (Lawson \& Brossart, 2001), are subject to intergenerational transmission; even moods, such as depression in the grandmother and mother, have been found to be transmitted to the granddaughter (Hammen, Shih \& Brennan, 2004). The major theories on intergenerational transmission, among them those that follow the behavioral approach (Bandura, 1971; Macewen, 1994), the family approach (Bowen, 1978; Fine \& Norris, 1989; Framo, 1981), and the psychoanalytic approach (Greenberg \& Mitchell, Bandura, 1971; Macewen, 1994 ; Shabad, 1993), all agree on this essential definition. The behavioral theories emphasize the process of modeling and reinforcement as a major type of learning in which children not only experience but also observe and listen to the behaviors of central figures in their lives (Bandura, 1977). The theory of social learning, which also pertains to the behavioral approach, is the most widely upheld theory in studies on intergenerational transmission, and is thus implemented as a basis for the research. It is also the theory of choice for explicating the findings of the current study. Children who repeatedly hear their parents say that the state creates poverty, that the state is responsible for the fact that the standard of living of working people is below the poverty line, that the state is to blame for the increase in the number of poor people, etc., will have the same attitude and approach when they become young adults. They too, will be of the opinion that there is a direct link between the state's institutions and policies and the existence of poverty.

Israel, in recent years, has seen the emergence of numerous groups that oppose the explicit move towards a political-economic oligarchy, a tendency which they claim is rooted in the ever-tightening connections between concentration of wealth and government policy. According to social leaders, the powers that be in the political realm are cultivating relationships, at the expense of other population groups, with a small faction that holds most of the country's wealth. Resentment and lack of trust in the system have permeated the core of Israeli consciousness, and these attitudes have been transmitted from parent to child.

It should be noted that many of the studies that examine intergenerational transmission report facing methodological difficulties, such as the lack of an equivalent control group, the use of inappropriate instruments (Ijzendoorn, 1992), and the use of too narrow a sample resulting in inflated values for the incidence of the intergenerational transmission (Almagor \& Leon, 1989; Bartle \& Anderson, 1991).

Some studies have demonstrated the effects of intergenerational transmission on loneliness (Lobdell \& Perlman, 1986), parenting styles (Ijzendoorn, 1992), and risk behaviors such as drug use, alcohol abuse and smoking (Corvo \& Carpenter, 2000). Studies of second generation Holocaust survivors have found intergenerational transmission effects also in aspects of control, depressive moods, and anxiety (Almagor \& Leon, 1989).

It may be assumed that residential proximity and frequent family gatherings, especially as is typical of religiously traditional families, increase the effects of intergenerational transmission. Presumably, in the current study all three generations were raised in families that believe in the values of social justice and in the government's responsibility for the welfare of its country's inhabitants. It is quite likely that having these values inculcated in the various generations of a family may be the reason for the decision taken by these grandchildren to pursue a career in social work.

The pursuit of social justice, exemplified in caring for the weak and the needy, is inherent to the field of social work. This study's findings pertaining to the attitudes exhibited by the youngest generation (i.e., social work students) are similar to those reported in other studies that analyzed social work students' attitudes regarding the causes and reasons for the phenomenon of poverty. An international study (Weiss, Gal \& Dixson, 2003) found that social work students from ten different nationalities (among them Hungarian, German, Australian, Hong-Kong, and Zimbabweans) all preferred the socio-structural explanation for the causes of poverty in society. In Israel too, social work schools, along with instilling the values inherent to the profession, emphasize the pursuit of social justice throughout the learning process (Banks, 2001; Carvalho, Wanderlet \& Mendes, 2003).

In the current study, participants of the youngest generation were not differentiated according to their year of study; therefore, it was impossible to assess the impact of the learning process or compare it with the effect of intergenerational transmission. It is recommended that future studies on this issue make an attempt to conduct such a comparison, so as to better understand the relative impact of an academic education that promotes professional social work values and contrast it with the effects of intergenerational transmission.

Another finding in the current study demonstrated that the majority of women in all three generations attributed the greatest importance to the socio-structural explanation for the causes of poverty. Women preferred also that the state take steps to expand social welfare programs and increase the budgets allocated to these programs, as the best way to 
help people overcome poverty. This finding corresponds with those of previous studies, which found that women more than men accept the social explanation for the existence of poverty. Thus, for example, Cryns (1977) found that male graduate students were less supportive of the social explanation than were undergraduate students that they preferred the explanation that attributes the condition of poverty to individual responsibility. Also Sun (2001) found that women more than men adhered to the socio-structural explanation. At this point it is important to note that in the current study, not only the youngest generation of female social work students but women of all three generations tended to prefer the social-structural explanation. Given that social work is considered a female profession, it is possible that it was the transmission of these attitudes from one generation of women to the next that led these students to choose social work and the pursuit of social justice as a profession.

A review of the research literature reveals that mother-daughter affinities were greater than father-son affinities. The gender effect is also demonstrated by the finding that the similarities between mother and daughter attitudes are greater than those found between mother and son attitudes (Bandura, Ross \& Ross, 1963; Bartle \& Anderson, 1991). Thus, the findings of a meta-analysis conducted by Stith, Rosen, Middelton, Busch, Lundeberg and Carlton (2000) support the hypothesis of intergenerational transmission of family violence and suggest that transmission between generations is gender based. Consequently, through imitation, girls learn the role of victim from their mothers, while boys learn the role of aggressor from their fathers. Intergenerational transmission is applicable also to the field of risk behaviors, such as drug use, alcohol abuse and smoking. There is significant evidence of substance and alcohol abuse among parents of drug and alcohol abusers, and evidence of smoking among parents of smokers, which reinforces the hypothesis of intergenerational transmission, mostly between fathers and sons (White, Johnson \& Buyske, 2000).

Most of the studies that deal with gender-based intergenerational transmission emphasize the transmission of behaviors, rather than transmission of attitudes or stereotypes. There are very few gender-based intergenerational transmission studies in general, and those that consider intergenerational transmission of attitudes towards poverty are even fewer. It is suggested that additional studies be conducted in order to understand the effects of gender on intergenerational transmission in regard to various attitudes.

Another interesting finding of the current study was about the nationality of the participants: Jewish participants in all three generations preferred the social explanation for poverty to the emotional-mental or the motivational explanations. Arab participants in general preferred the emotional-mental to either of the other two explanations for poverty. However, participants of the youngest generation preferred the social-structural explanation to either the emotional-mental or the motivational explanations.

One explanation for this finding is related to the traditional structure of the Arab family. In many cases, especially among the population that follows tradition and resides in rural areas, the Arab family functions within a clan structure. Despite the fact that Arab society is undergoing change due to modernization processes, it still functions in family collectives, whereby the family takes care of its members, and the collective takes precedence over the individual (Al-Haj, 1989; 1995). The family therefore takes care of all of its members' needs, and in return, each member invests as much effort and/or resources as possible in the family. Consequently, the responsibility for an individual's welfare lies with his or her family-community rather than with the state. If one of the members, always in this case a male who is the head of a family unit, cannot provide for his family's needs, it must be because he has either a motivational or an emotional-mental problem that keeps him from fulfilling his responsibilities (Al-Krenawi, 2008).

As previously noted, the majority of participants in the current study preferred that the state take measures to expand welfare programs and increase the budgets allocated to such programs in order to help people overcome poverty. The expansion of welfare programs indicates a high degree of commitment to social justice and equality (Banks, 2001). According to the author of the current study, the profession of social work and its practitioners has an obligation to support social changes intended to increase opportunities available to disadvantaged community members. The advancement of social justice and the expansion of relevant intervention programs require taking into account the issue of multiculturalism, and honing skills for critical and independent thought, particularly in regard to existing policies. Daring is also essential, if social workers are to think and act in a more radical manner than they have heretofore.

In terms of the means used to overcome the problem of poverty, the Jewish participants in all three generations preferred the expansion of welfare programs to reducing the amounts granted through welfare benefits, and indicated that the least preferable alternative was individual psychological treatment $(\mathrm{p}<0.01)$. The Arab participants, interestingly, indicated a preference for the reduction --rather than the expansion-- of welfare programs and benefits, as a means of overcoming the problem of poverty. They too indicated that the least preferable alternative was individual psychological treatment $(\mathrm{p}<0.05)$.

Another interesting finding related to the youngest generation of Arab participants who are undergraduate and graduate students of social work (the latter being certified social workers already licensed to work in the community). These 
participants preferred the expansion of welfare programs and benefits $(p<0.01)$, in contrast to the preferences indicated by their parents and grandparents. This finding may be related to the process of modernization that Arab society in Israel is undergoing.

\section{Conclusion}

The similarity revealed between Jewish and Arab students suggests that the influence of shared concerns and the common pursuit of social justice is stronger than the differences that stem from nationality. Thus, this finding gives cause for optimism with regard to the young generation of social workers, whose devotion to the welfare of others is not bound by nationality.

\section{References}

Al-Haj, M. (1989). Social research on family lifestyles among Arabs in Israel. Journal of Comparative Family Studies, 20(2), 175-195.

Al-Haj, M. (1995). Kinship and modernization in developing societies: The emergence of instrumentalized kinship. Journal of Comparative Family Studies, 26, 311-328.

Almagor, M., \& Leon, G. R. (1989) Transgenerational effects of the concentration camp experience. In P. Marcus \& A. Rosenberg (Eds.) Healing their wounds: Psychotherapy with Holocaust survivors and their families. New York: Praeger.

Amato, P. R. (1996). Explaining the intergenerational transmission of divorce. Journal of Marriage and the Family 58, 628-641. http://dx.doi.org/10.1177/0192513X10383944

Bandura, A. (Ed.). (1971). Psychological modeling: Conflicting theories. Chicago: Aldine-Atherton.

Bandura, A. (1977). Social learning theory. Englewood Cliffs, NJ: Prentice Hall.

Bandura, A., Ross, D., \& Ross, S. A. (1963). Vicarious reinforcement and imitative learning. Journal of Abnormal and Social Psychology, 67, 601-607. http://dx.doi.org/10.1037/h0045550

Bartle, S. E., \& Anderson, S. A. (1991). Similarity between parents and adolescents levels of individuation. Adolescence, 26, 913-924.

Bowen, M. (1978). Family therapy in clinical practice. New York: Jason Aaronson.

Bullock, H. E., Williams, W. R., \& Limbert, W. M. (2003). Predicting support for welfare policies: The impact of attributions and beliefs about inequality. Journal of Poverty, 7, 35- 56. http://dx.doi.org/10.1300/J134v07n03_03

Corvo, K., \& Carpenter, E. H. (2000). Effects of parental substance abuse on current levels of domestic violence: A possible elaboration of intergenerational transmission processes. Journal of Family Violence, 15, 123-135. http://dx.doi.org/10.1023/a:1007557626788

Davis, \& Wainwright, S. (2005). Combating poverty and social exclusion: Implications for social work education. Social Work Education, 24, 259-273. http://dx.doi.org/10.1080/02615470500050453

Fine, M., \& Norris, J. E. (1989). Intergenerational relations and family therapy research: What we can learn from other disciplines. Family Process, 28, 301-315. http://dx.doi.org/10.1111/j.1545-5300.1989.00301

Framo, J. L. (1981). The Integration of Marital Therapy with Sessions with Family of Origin.

In, A., Gurman, S., \& Kinskern, D. P. (Eds.), Handbook of Family Therapy (pp. 133-157). New-York: Brunner-Mazel.

Hammen, C., Shih, J. H., \& Brennan, P. (2004). Intergenerational transmission of depression :test of Interpersonal Stress Model in a community sample .Journal of Consulting \& Clinical Psychology, 72(3), 511-522. http://dx.doi.org/10.1037/0022-006X.69.2.284

Ijzendoorn, M. H. (1992). Intergenerational transmission of parenting: A review of studies in nonclinical populations. Developmental Review, 12, 76-99. http://dx.doi.org/10.1016/0273-2297(92)90004-L.

Kilty, K. M., \& Segal, E. A. (Eds.). (2003). Rediscovering the other America: The continuing crisis of poverty and inequality in the United State. New York: Haworth Press.

Lawson, D. M., \& Brossart, D. F. (2001). Intergenerational transmission: individuation and intimacy across three generations. Family Process, 40(4), 429-441.

Lobdell, J., \& Perlman, D. (1986). The intergenerational transmission of loneliness: A study of college females and their parents. Journal of Marriage and the Family, 48, 589-595.

Macarov, D. (2003). What the market does to people: Privatization, Globalization and poverty: Atlanta, GA.: Clarity 
Press.

Macewen, K. E. (1994). Refining the intergenerational transmission hypothesis. Journal of Interpersonal Violence, 9, 350-365. http://dx.doi.org/10.1177/088626094009003005

NASW - National Association of Social Workers. (1999). Code of ethics. Washington, DC: Author.

Pearlin, L .I., Lieberman, M .A., Menaghan, E .G., \& Mulan (1981). The stress process. Journal of Stress and Social Behavior, 22, 337-356. http://dx.doi.org/10.2307/2136676.

Resser, L. C., \& Epstein, I. (1987). Social workers' attitudes toward poverty and social action: 1968-1984. Social Service Review, 61, 610-622. http://dx.doi.org/10.1086/644481

Rehner, T., Ishee, J., Salloum, M., \& Velasques, D. (1997). Mississippi social workers' attitudes toward poverty and the poor. Journal of Social Work Education, 33, 131-142. http://dx.doi.org/10.1177/0958928712456575

Shabad, P. (1993). Resentment, indignation, entitlement: The transformation of unconscious wish into need. Psychoanalytic Dialogues, 3, 481-494. http://dx.doi.org/10.1080/10481889309538988.

Schwartz, S., \& Robinson, M. M. (1991). Attitudes towards poverty during undergraduate education. Journal of Social Work Education, 27, 290-296. http://dx.doi.org/10.1093/obo/9780195390155-0062

Segal, E. A. (2007). Social empathy: A tool to address the contradiction of working but still poor. Family in Society, 88(3), 333-337. http://dx.doi.org/10.1606/1044-3894.3642.

Spicker, P. (2007). The Idea of Poverty. The Policy Press. University of Bristol.

Stith, S. M., Rosen, K. H., Middelton, K. A., Busch, A. L., Lundeberg, K., \& Carlton, R. P. (2000). The intergenerational transmission of spouse abuse: A meta-analysis. Journal of Marriage and the Family, 62, 640-654. http://dx.doi.org/10.1111/j.1741-3737.2000.00640.

Sun, A. (2001). Perceptions among social work and nun-social work studies concerning causes of poverty. Journal of Social Work Education, 37, 161-173. http://dx.doi.org/10.1177/0958928712456575

Weiss, I., Gal, J., \& Dixson, J. (Eds.). (2003). Professional ideologies and preferences in social work: A global study: Westport, Conn: Praeger.

White, H. R., Johnson, V., \& Buyske, S. (2000). Parental modeling and parenting behavior effects on offspring alcohol and cigarette use - A growth curve analysis. Journal of Substance Abuse, 12, 287-310. http://dx.doi.org/10.1177/0958928712456575

Wolfinger, N . H. (2000). Beyond the intergenerational transmission of divorce. Journal of Family Issues 21, 10611086. http://dx.doi.org/10.1177/019251391012001003

\section{(cc) BY}

This work is licensed under a Creative Commons Attribution 3.0 License. 